\title{
Spectroscopic Estimation of Geometrical Structure Elucidation in Natural $\mathrm{SiO}_{2}$ Crystal
}

\author{
Bhaskar J. Saikia* \\ Department of Physics, Anandaram Dhekial Phookan College, Nagaon-782002, India \\ *Corresponding author: vaskar_r@rediffmail.com
}

Received October 31, 2014; Revised November 19, 2014; Accepted December 15, 2014

\begin{abstract}
This study demonstrate for the first time the geometrical structure change relationship of natural quartz crystal structures with its purity through infrared spectroscopy. Systemetatic investigations of geometrical structure changes of the quartz crystals have been carried out in mid infrared region $500-1000 \mathrm{~cm}^{-1}$ based on the assignment of infrared bands of the structural group $\mathrm{SiO}_{4}$ tetrahedra. The compositional and structural studies were carried out at room temperature by using X-ray fluorescence (XRF) and Fourier transform infrared (FTIR) spectroscopic techniques. The variation of geometrical structure of quartz crystals has been ascertained by comparing the infrared and X-ray fluorescence results. Results depict the variation of crystal size and shift of characteristic peak positions of the studied samples are depends on its purity. The infrared investigation is found to be good for structure elucidation and changes of geometrical crystal structures of the natural quartz crystals.
\end{abstract}

Keywords: quartz crystal, infrared spectroscopy, XRF, structure elucidation

Cite This Article: Bhaskar J. Saikia, "Spectroscopic Estimation of Geometrical Structure Elucidation in Natural $\mathrm{SiO}_{2}$ Crystal.” Journal of Materials Physics and Chemistry, vol. 2, no. 2 (2014): 28-33. doi: 10.12691/jmpc-2-2-3.

\section{Introduction}

Quartz is a pure mineral that has the chemical formula $\mathrm{SiO}_{2}$ and is crystalline in structure. It cannot exist in slab form in a pure state. Quartz has a density of $2.649 \mathrm{~g} / \mathrm{cm}^{3}$ with trigonal crystal system in $\mathrm{D}_{3}(32)$ crystallographic group. Quartz, or $\alpha$-quartz, is the mineral form of $\mathrm{SiO}_{2}$ stable at low temperatures and pressures. Quartz crystals changes from $\alpha$ to $\beta$ quartz crystal at a temperature of $573^{\circ} \mathrm{C}$ because of phase transition. This phase transition is reversible, but transition from $\beta$ quartz crystal to $\alpha$ crystal does not take place homogeneously. Quartz is colorless in its pure form, but due to trace minerals, many colors are found in nature. A quantitative analysis of trace elements in quartz crystals has been reported by many authors [1-5]. Quartz has an exceptionally stable atomic configuration of Si-O bonds that allows only a minimal amount of other elements into its structure. In addition to structural impurities, quartz frequently contains solid and fluid inclusions. It is always nearly pure silica with less than 0.2 percent of total impurities.

Information about structural defects in quartz crystals can be obtained from Fourier-transform infrared (FTIR) spectroscopy [6-11]. The crystal structure analysis discussed here is necessary to investigate the correlation between the trace oxide inclusions; characteristic infrared band shift and crystal face size in the crystal growth [12]. The actual mechanisms responsible for the variation in size and shape of individual crystal faces are, in fact, not well understood [13]. The major goal of this type of analysis is to understand the crystal growth mechanisms.
In the present work we address the IR and XRF technique for estimation of geometrical structure studies of some selected quartz crystals of northeastern India.

\section{Experimental}

The estimation of the geometrical structures of the natural quartz crystals (Figure 1) is done by calculating the each crystal faces of the studied samples using slide calipers. Five independent measurements were carried out for each face of each sample and the average of the crystal faces of the samples is presented here.

A part of the samples was crushed into fine powder (75 $\mu$ ) for analysis, by using agate mortar. The powdered samples $(0.25 \mathrm{~g})$ are put into platinum crucibles and $\mathrm{HNO}_{3}$ (conc.), $\mathrm{HCl}, \mathrm{H}_{2} \mathrm{O}_{2}$ and $\mathrm{HF}$ are added in a proportion of 5 : 2: 1: $2 \mathrm{ml}$. Crucibles are heated on hot plate and the solution evaporated to near dryness. After that $2 \mathrm{ml} \mathrm{HF}$ are added few times until precipitate of $\mathrm{SiO}_{2}$ is eliminated as $\mathrm{SiF}_{4}$ vapors. After cooling down to the room temperature, a mixture of $\mathrm{HCl}$ (conc.) and redistilled water at a ratio 2: $5 \mathrm{ml}$ is added, the solution transferred in $50 \mathrm{ml}$ volumetric flasks and filled up with redistilled water. Then $0.5 \mathrm{~g}$ of powdered sample is put in a glass beaker and a mixture of redistilled water and $\mathrm{HCl}$ (conc.) in a ratio 15: $20 \mathrm{ml}$ is added and the solution evaporated to near dryness. The residue is dissolved with $10 \mathrm{ml} 1 \%$ tin, and $\mathrm{SiO}_{2}$ precipitated and coagulated. Precipitate is filtered and washed with $\mathrm{HCl}$ solution in a ratio 5:95 ml. Filter paper and residue are transferred into a platinum crucible and heated on $1000^{\circ} \mathrm{C}$ for $10 \mathrm{~min}$. Crucible is weighed and the content of $\mathrm{SiO}_{2}$ calculated. Then $0.5 \mathrm{~g}$ of powdered 
sample is put in a glass beaker and a mixture of redistilled water and $\mathrm{HCl}$ (conc.) in a ratio 15: $20 \mathrm{ml}$ is added and the solution evaporated to near dryness. The residue is dissolved with $10 \mathrm{ml} 1 \%$ tin, and $\mathrm{SiO}_{2}$ precipitated and coagulated. Precipitate is filtered and washed with $\mathrm{HCl}$ solution in a ratio 5:95 ml. Filter paper and residue are transferred into a platinum crucible and heated on $1000^{\circ} \mathrm{C}$ for $10 \mathrm{~min}$. Crucible is weighed and the content of $\mathrm{SiO}_{2}$ calculated.

The powdered sample was homogenized in spectrophotometric grade $\mathrm{KBr}(1: 20)$ in an agate mortar and was pressed $3 \mathrm{~mm}$ pellets with a hand press. We tried to minimize the grinding time to avoid the deformation of the crystal structure, the ion exchange and the water absorption from atmosphere. The infrared spectra was acquired using Perkin-Elmer system 2000 FTIR spectrophotometer with helium-neon laser as the source reference, at a resolution of $4 \mathrm{~cm}^{-1}$. The spectra were taken in transmission mode in the region $400-4000 \mathrm{~cm}^{-1}$. The room temperature was $31^{\circ} \mathrm{C}$ during the experiment.

The composition of the quartz crystals was determined by using Philips X-ray fluorescence (XRF) machine. The method of sample preparation for investigation is discussed elsewhere [14,15,16]. Five independent measurements were carried out and the average composition of the sample is presented here. The chemical composition of the samples was also observed by electron probe micro-analyzer (EPMA). Energy Dispersive X-ray (EDX) measurements were carried out by using scanning electron microscope (JEOL JSM - 840 A) in EDX mode with a filament current of $100 \mu \mathrm{A}$ and an accelerating voltage of $20 \mathrm{kV}$ probe current $45 \mathrm{nA}$ and counting time 60 seconds. Polished thin sections were investigated for the elemental composition. The calibration and reproducibility of this apparatus is discussed elsewhere
[17]. In X-ray fluorescence method, typical uncertainty involved in oxide analyses was about $0.01 \mathrm{wt} \%$.

\section{Results and Discussion}

The characteristic of infrared bands associated with quartz crystals are in the range of $1200-400 \mathrm{~cm}^{-1}$ [18]. In the studied samples the $\mathrm{SiO}_{4}$ tetrahedra exhibits $\mathrm{Si}-\mathrm{O}$ asymmetrical stretching vibration (v3) in between 1175$1080 \mathrm{~cm}^{-1}$, Si-O symmetrical stretching vibration $(v 1)$ in between 784.11-779.11 $\mathrm{cm}^{-1}$, Si-O symmetrical bending vibration ( $v 2$ ) in between 696.21-694.44 $\mathrm{cm}^{-1}$, and $\mathrm{Si}-\mathrm{O}$ asymmetrical bending vibration ( $v 4$ ) in between 466-463 $\mathrm{cm}^{-1}$ (Figure 2). The peak at $695 \mathrm{~cm}^{-1}$ arises due to the octahedral site symmetry and is unique to the crystalline materials. The tetrahedral-tetrahedral ion vibration affects the band at $778 \mathrm{~cm}^{-1}$ in silicates, the tetrahedral dimension is generally considered to be little effected by pressure and temperature [19-22]. The tetrahedral site symmetry is stronger to that of octahedral site symmetry. Therefore, for any structural change, the damage occurs first in octahedral site symmetry then in tetrahedral site symmetry. The intensity of the bands due to the vibrations of these two symmetries will provide direct information on the crystallinity and crystal growth. It is well known that in the infrared spectra of amorphous silica the symmetrical bending vibration of the Si-O group found at $695 \mathrm{~cm}^{-1}$ is missing [20,21,22]. Therefore, the symmetrical bending vibrations of $\mathrm{Si}-\mathrm{O}$ group obtained at $695 \mathrm{~cm}^{-1}$ is diagnostic peak in determining the short range parameter of the quartz, whether it is crystalline or amorphous. We focused on these characteristic peaks 778 and $695 \mathrm{~cm}^{-1}$ of each samples to investigate the purity and structural relationship.

Table 1. Chemical compositions (\%wt) and amount of trace oxides or contaminations (\%wt) of the studied quartz crystals Composition (wt\%)

\begin{tabular}{|c|c|c|c|c|c|c|c|c|c|}
\hline \multirow[b]{2}{*}{ Sample } & & \multirow{2}{*}{$\begin{array}{c}\text { Amount of trace oxides } \\
\text { /contamination } \\
\text { (\%wt) }\end{array}$} \\
\hline & $\mathrm{SiO}_{2}$ & $\mathrm{Al}_{2} \mathrm{O}_{3}$ & $\mathrm{FeO}$ & $\mathrm{MgO}$ & $\mathrm{CaO}$ & $\mathrm{K}_{2} \mathrm{O}$ & $\mathrm{TiO}$ & $\mathrm{MnO}$ & \\
\hline Q-01 & 99.79 & 0.14 & 0.06 & -- & -- & -- & 0.003 & 0.005 & 0.21 \\
\hline Q-02 & 99.73 & 0.18 & 0.05 & -- & 0.02 & 0.01 & -- & 0.001 & 0.27 \\
\hline Q-03 & 99.76 & 0.13 & 0.09 & 0.001 & 0.01 & -- & 0.001 & -- & 0.24 \\
\hline Q-04 & 99.41 & 0.35 & 0.04 & 0.007 & 0.07 & 0.01 & 0.005 & 0.011 & 0.59 \\
\hline Q-05 & 99.49 & 0.21 & 0.14 & -- & -- & 0.06 & 0.009 & 0.010 & 0.51 \\
\hline Q-06 & 99.59 & 0.27 & 0.09 & 0.005 & 0.01 & -- & 0.003 & 0.001 & 0.41 \\
\hline Q-07 & 99.65 & 0.25 & 0.05 & -- & 0.01 & 0.02 & 0.001 & -- & 0.35 \\
\hline Q-08 & 99.69 & 0.17 & 0.12 & 0.002 & -- & -- & 0.001 & 0.003 & 0.31 \\
\hline Q-09 & 99.48 & 0.23 & 0.11 & -- & -- & 0.07 & 0.006 & 0.011 & 0.52 \\
\hline Q-10 & 99.61 & 0.12 & 0.20 & -- & 0.02 & -- & 0.008 & -- & 0.39 \\
\hline Q-11 & 99.71 & 0.13 & 0.09 & 0.040 & 0.01 & -- & 0.001 & -- & 0.29 \\
\hline Q-12 & 99.67 & 0.16 & 0.10 & 0.001 & -- & 0.04 & 0.003 & 0.005 & 0.33 \\
\hline
\end{tabular}

The chemical composition and purity level of the samples are depicted in the Table 1 and Table 2 respectively. The XRF result (Table 1) reveals 99.79 percent of $\mathrm{SiO}_{2}$ compositions with low grade of trace oxide of 0.21 percent in sample Q-01 and its size of average crystal faces are found to be the maximum value $1.4652 \mathrm{~cm}$ among the studied samples. In nearly pure silica, less than 0.2 percent of total impurities are generally observed. The impurity level of the sample Q-1 is found to be almost equal to the standard level of impurity. The crystallinity index of samples has been ascertained by the ratio of intensity of the characteristic peak at $778 \mathrm{~cm}^{-1}$ and $695 \mathrm{~cm}^{-1}$ and percent crystallinity is calculated by considering crystallinity index of Q-1(1.34) as standard whose impurity level is found to be lowest among the samples (Table 1). Generally the symmetrical bending vibration of $\mathrm{Si}-\mathrm{O}$ at $695 \mathrm{~cm}^{-1}$ is identical for crystalline phase. The calculated percent crystallinity and corresponding value of $\mathrm{SiO}_{2}$ composition of each sample are interpreted in Table 2 [22]. The low value of 
crystallinity index indicates that the sample has a poor crystalline form which is indicative of the impurities during crystallization. The intensity and position of these characteristic infrared peaks are affected by the inclusion. However, the inclusion affects the growth of the crystal size. Therefore, the correlations among crystallinity, inclusion and crystal faces are indicative measure of the purity of the quartz crystals. Generally the theoretical difference of tetrahedral and octahedral site symmetry is $83 \mathrm{~cm}^{-1}$. The characteristic peaks positions (778 and 695 $\mathrm{cm}^{-1}$ ) of the studied samples are described in the Table 3., and is vary with contaminations which affect the size of the crystals in its natural growth. The change of average crystal faces is calculated by considering the maximum size of average crystal faces of Q-1 $(1.4652 \mathrm{~cm})$ as standard.

Comparative evaluation of XRF and IR results shows almost similar estimation values for percent of $\mathrm{SiO}_{2}$ composition and percent crystallinity with each other for all samples (Table.2). The Table 2 also depicts the variation of crystal faces/size with purity level of the crystals. The maximum infrared peak shift $6.08 \mathrm{~cm}^{-1}$ is observed in the sample Q-04 with maximum trace oxide and $\mathrm{SiO}_{2}$ compositions $0.59 \%$ wt and $99.41 \%$ \%t. respectively. Similarly the minimum infrared peak shift $1.29 \mathrm{~cm}^{-1}$ is observed in the sample Q-01 with minimum trace oxide and $\mathrm{SiO}_{2}$ compositions $0.21 \%$ wt and $99.79 \%$ \%t. respectively. The crystallinity of the samples are calculated by considering the sample Q-01 taken as standard since it has less peak shift and minimum trace oxide. The infrared result shows the crystallinity are $100 \%$ and $87.31 \%$ respectively for the samples Q-01 and Q-04.

It is well known that temperature and pressure influences the growth of quartz crystals. Apart from pressure and temperature, the sizes of the naturally occurring quartz crystals are affected by its trace composition. It is emphasized that the geometrical size of the natural quartz crystal can be considered one of the indicators of purity. The composition of the trace oxides are also affects the purity as well as the intensity of the characteristic infrared peaks of the samples. Table 2 signify that the intensity of the infrared characteristic peaks are found to be maximum in the sample Q-01 in which the corresponding trace oxides are have a marginal value.

Table 2. Percent transmittance of tetrahedral and octahedral peaks (\%T), tetrahedral and octahedral peak intensities ( $\AA$ ), crystallinity index, percent crystallinity index, and composition of $\mathrm{SiO}_{2}$ (\%wt) among the studied quartz crystals

\begin{tabular}{|c|c|c|c|c|c|c|c|c|c|}
\hline \multirow{2}{*}{ Sample } & \multicolumn{8}{|c|}{ Composition (wt\%) } & \multirow{2}{*}{$\begin{array}{c}\text { Amount of trace oxides } \\
\text { /contamination } \\
\text { (\%wt) }\end{array}$} \\
\hline & $\mathrm{SiO}_{2}$ & $\mathrm{Al}_{2} \mathrm{O}_{3}$ & $\mathrm{FeO}$ & $\mathrm{MgO}$ & $\mathrm{CaO}$ & $\mathrm{K}_{2} \mathrm{O}$ & $\mathrm{TiO}$ & $\mathrm{MnO}$ & \\
\hline Q-01 & 99.79 & 0.14 & 0.06 & -- & -- & -- & 0.003 & 0.005 & 0.21 \\
\hline Q-02 & 99.73 & 0.18 & 0.05 & -- & 0.02 & 0.01 & -- & 0.001 & 0.27 \\
\hline Q-03 & 99.76 & 0.13 & 0.09 & 0.001 & 0.01 & -- & 0.001 & -- & 0.24 \\
\hline Q-04 & 99.41 & 0.35 & 0.04 & 0.007 & 0.07 & 0.01 & 0.005 & 0.011 & 0.59 \\
\hline Q-05 & 99.49 & 0.21 & 0.14 & -- & -- & 0.06 & 0.009 & 0.010 & 0.51 \\
\hline Q-06 & 99.59 & 0.27 & 0.09 & 0.005 & 0.01 & -- & 0.003 & 0.001 & 0.41 \\
\hline Q-07 & 99.65 & 0.25 & 0.05 & -- & 0.01 & 0.02 & 0.001 & -- & 0.35 \\
\hline Q-08 & 99.69 & 0.17 & 0.12 & 0.002 & -- & -- & 0.001 & 0.003 & 0.31 \\
\hline Q-09 & 99.48 & 0.23 & 0.11 & -- & -- & 0.07 & 0.006 & 0.011 & 0.52 \\
\hline Q-10 & 99.61 & 0.12 & 0.20 & -- & 0.02 & -- & 0.008 & -- & 0.39 \\
\hline Q-11 & 99.71 & 0.13 & 0.09 & 0.040 & 0.01 & -- & 0.001 & -- & 0.29 \\
\hline Q-12 & 99.67 & 0.16 & 0.10 & 0.001 & -- & 0.04 & 0.003 & 0.005 & 0.33 \\
\hline
\end{tabular}

Table 3. The tetrahedral and octahedral frequencies $\left(\mathrm{cm}^{-1}\right)$, theoretical and observed differences of tetrahedral and octahedral frequencies (cm ${ }^{1}$ ), size of average crystal faces $(\mathrm{cm})$, and change of average crystal face $(\mathbf{c m})$ among the studied quartz crystals

\begin{tabular}{|c|c|c|c|c|c|c|c|}
\hline \multirow[b]{2}{*}{ Sample } & \multicolumn{2}{|c|}{ Characteristic infrared frequencies } & \multirow{2}{*}{$\begin{array}{c}\text { Observed difference } \\
\text { of Tetrahedral \& } \\
\text { Octahedral peak } \\
\left(\mathrm{cm}^{-1}\right)\end{array}$} & \multirow{2}{*}{$\begin{array}{l}\text { Theoretical difference } \\
\text { of Tetrahedral \& } \\
\text { Octahedral peak } \\
\left(\mathrm{cm}^{-1}\right)\end{array}$} & \multirow{2}{*}{$\begin{array}{l}\text { Observed and } \\
\text { theoretical } \\
\text { peak shift } \\
\left(\mathrm{cm}^{-1}\right)\end{array}$} & \multirow{2}{*}{$\begin{array}{c}\text { Size of } \\
\text { average } \\
\text { Crystal } \\
\text { faces } \\
(\mathrm{cm})\end{array}$} & \multirow{2}{*}{$\begin{array}{l}\text { Change of } \\
\text { average } \\
\text { crystal face } \\
\text { (cm) }\end{array}$} \\
\hline & $\begin{array}{c}\text { Tetrahedral } \\
\left(778 \mathrm{~cm}^{-1}\right)\end{array}$ & $\begin{array}{l}\text { Octahedral } \\
\left(695 \mathrm{~cm}^{-1}\right)\end{array}$ & & & & & \\
\hline Q-01 & 779.42 & 695.13 & 84.29 & 83 & 1.29 & 1.4652 & 0 \\
\hline Q-02 & 780.51 & 696.21 & 84.30 & 83 & 1.30 & 1.4175 & 0.477 \\
\hline Q-03 & 779.23 & 694.89 & 84.34 & 83 & 1.34 & 1.3361 & 1.291 \\
\hline Q-04 & 784.11 & 695.03 & 89.08 & 83 & 6.08 & 0.8273 & 6.379 \\
\hline Q-05 & 782.43 & 695.21 & 87.47 & 83 & 4.47 & 0.9479 & 5.173 \\
\hline Q-06 & 783.23 & 696.01 & 87.22 & 83 & 4.22 & 1.0754 & 3.898 \\
\hline Q-07 & 779.87 & 694.92 & 84.95 & 83 & 1.95 & 1.0542 & 4.110 \\
\hline Q-08 & 779.46 & 694.44 & 85.02 & 83 & 2.02 & 1.2391 & 2.261 \\
\hline Q-09 & 781.55 & 695.26 & 86.29 & 83 & 3.29 & 0.9883 & 4.769 \\
\hline Q-10 & 779.27 & 694.49 & 84.78 & 83 & 1.78 & 1.0747 & 3.905 \\
\hline Q-11 & 779.11 & 694.75 & 84.36 & 83 & 1.36 & 1.1533 & 3.119 \\
\hline Q-12 & 780.32 & 695.38 & 84.94 & 83 & 1.94 & 1.1416 & 3.236 \\
\hline
\end{tabular}

The shift of the characteristic peaks of each samples are ascertain from the theoretical peak difference of 778 and $695 \mathrm{~cm}^{-1}$. The variation of the average crystal face is estimated from the maximum face size of sample Q-01. Table 3 infers the shift of the characteristic peaks and variation of the geometrical crystal structure respectively. The shift of peak positions in the tetrahedral and octahedral site symmetry indicates the effect of trace minerals or oxides associated with the quartz crystal during the crystal growth or formation. The trace ion oxide or elements are responsible for the colour variation of the quartz crystals. The milky white colour of quartz minerals is due to the presence of traces of $\mathrm{Ca}$, the appearance of black colour is the result of the existence of 
$\mathrm{Pb}, \mathrm{Mn}$ and $\mathrm{Al}$ impurities, and the occurrence of red and green colour is due to $\mathrm{Fe}, \mathrm{Ti}$ and $\mathrm{Cr}$ trace impurities respectively. The smoky colour of quartz may also cause by low levels of ionising radiation induced by the decay of radioactive elements in neighbouring minerals (e.g. ${ }^{40} \mathrm{~K}$ in alkali feldspar) [23]. The selected samples are almost transparent with light colour variation (Figure 1).

The plot exhibits that, as the presence of trace oxides in the quartz samples decreases the average crystal faces are increases with a very strong correlation $\left(\mathrm{R}^{2}=0.9185\right)$. The change of position in the infrared characteristic peaks are also inversely proportional to the size of average crystal faces of the studied crystal with a strong correlation $\left(\mathrm{R}^{2}=\right.$ 0.8177). However, the value of crystillinity index in the observed crystals has directly proportional to the size of average crystal faces of the crystals (Figure 3 ). The value of crystillinity index and the size of average crystal faces of the crystals are depicts a strong correlation $\left(\mathrm{R}^{2}=\right.$ 0.8132).

The strong correlation $\left(\mathrm{R}^{2}=0.837\right)$ between the trace oxide or contaminations with the changes of infrared characteristic peaks positions exhibits that the change of position in the infrared characteristic peaks are directly related to the trace oxide or contaminations of the quartz crystals. The value of characteristic infrared peak shift is increases with increasing of the value of trace oxides in the sample. The values of crystallinity indices are decreases as increasing the value of trace oxides or contaminations. It also affects the infrared characteristic peak shifts, the infrared characteristic peak shift decreases as the value of crystallinity indices are increases (Figure 3).
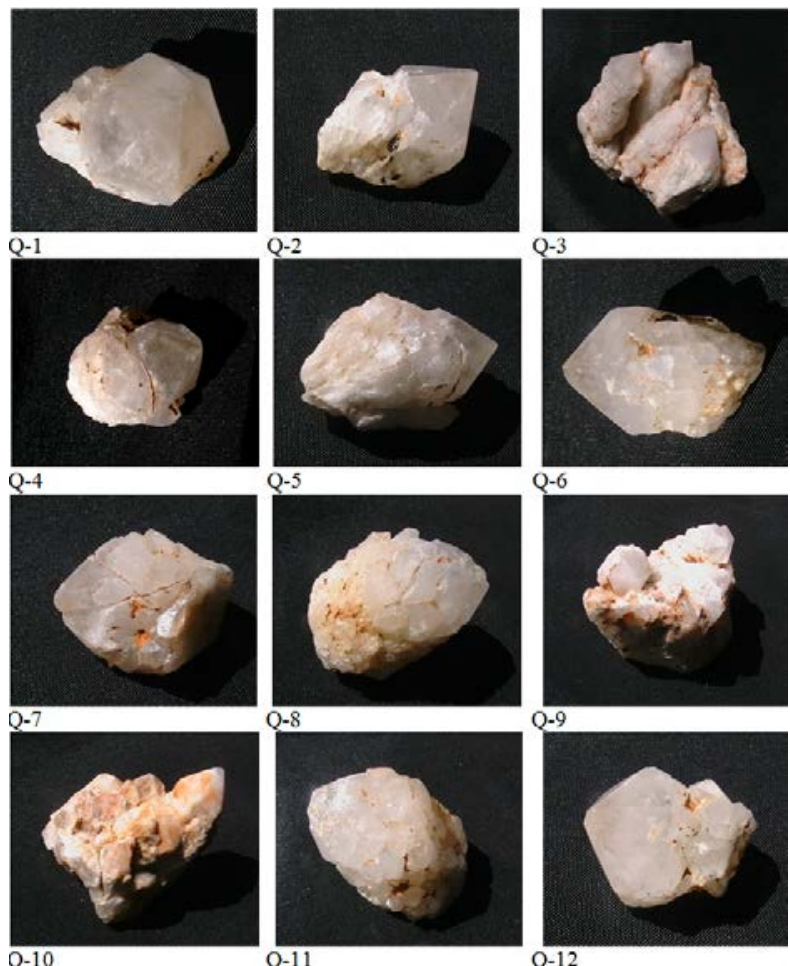

Figure 1. Photograph of studied quartz crystals
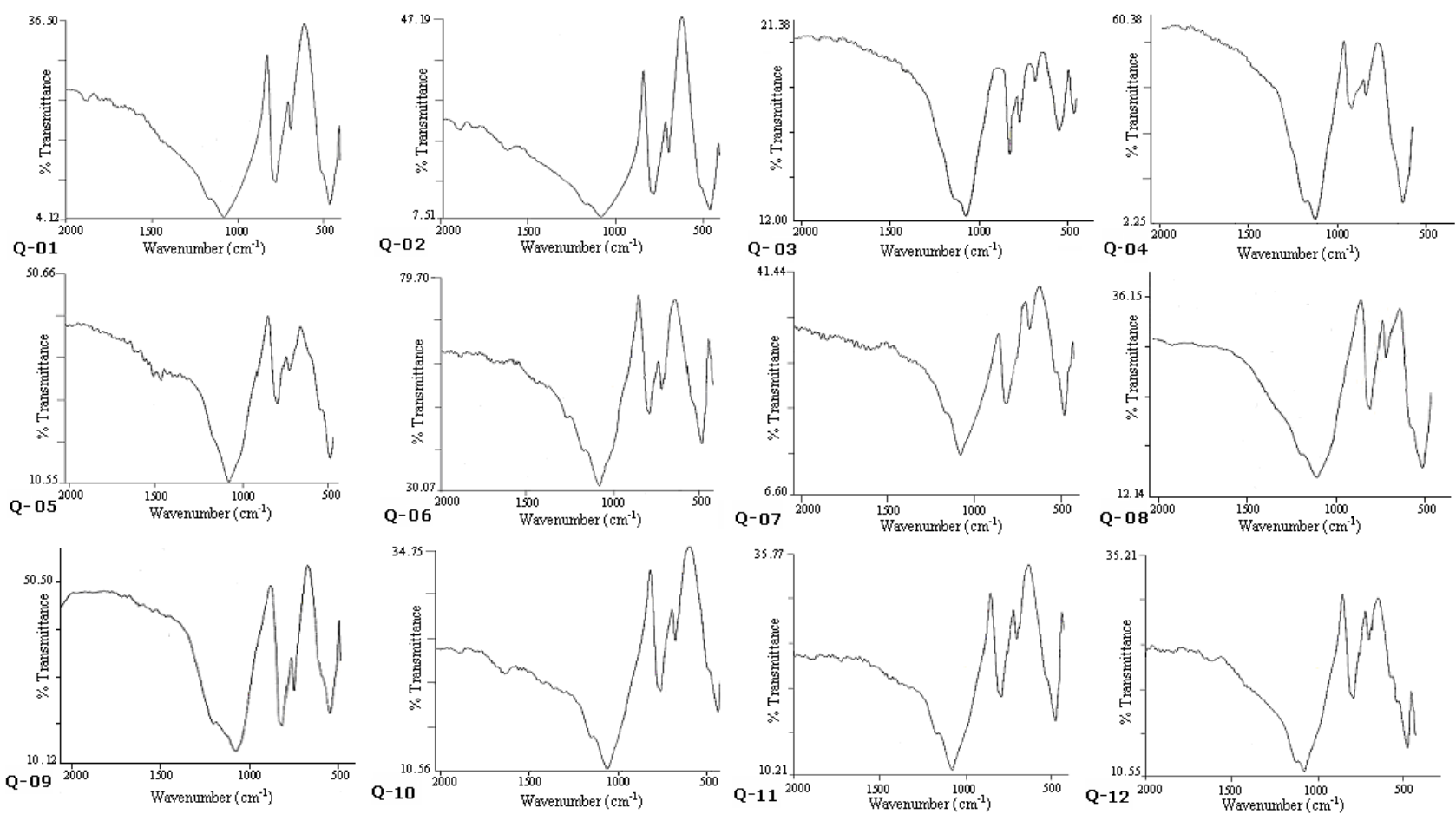

Figure 2. FTIR spectra of the studied quartz crystal samples in the finger print region

The of changes in average crystal faces size of the observed crystals with the value of trace oxides concentrations and the change of position in the infrared characteristic peaks are directly proportional to each other with same correlation values with that of the size of the average crystal faces. The values of crystallinity index and changes in average crystal faces size exhibits same correlation values with that of average crystal faces size, but in reverse order (Figure 3).

\section{Conclusion}

We observed the shift of infrared characteristic peaks is directly related to the trace oxide or contaminations of the sample. The average crystal faces of the samples are decreases with increasing the trace oxide or contamination concentrations. Likewise, the shift of infrared 
characteristic peaks is increases with increasing of trace oxide or contamination concentrations. It is found that the highest value of trace oxide or contamination exhibits maximum peak shift. The trace oxide or contamination concentrations are strongly correlated with average crystal faces, crystallinity index and shift of the infrared characteristics peak with a strong correlation value 0.9185 , 0.8231 and 0.8370 respectively. The shift of tetrahedraloctahedral site symmetry bands with the size of crystal faces of the quartz crystal throws light on the crystal growth and pressure-temperature (phase transition) during the process of formation. The variation of the associated trace oxides / minerals represents a good for structure elucidation and changes of geometrical shape of the quartz crystals. The IR, XRF and crystal faces measurement represents a quite comparable significant effect of trace level impurities in the process of crystal growth. Hence it can be conclude that the IR method can be used for monitoring the compositional relationship of quartz crystal growth.
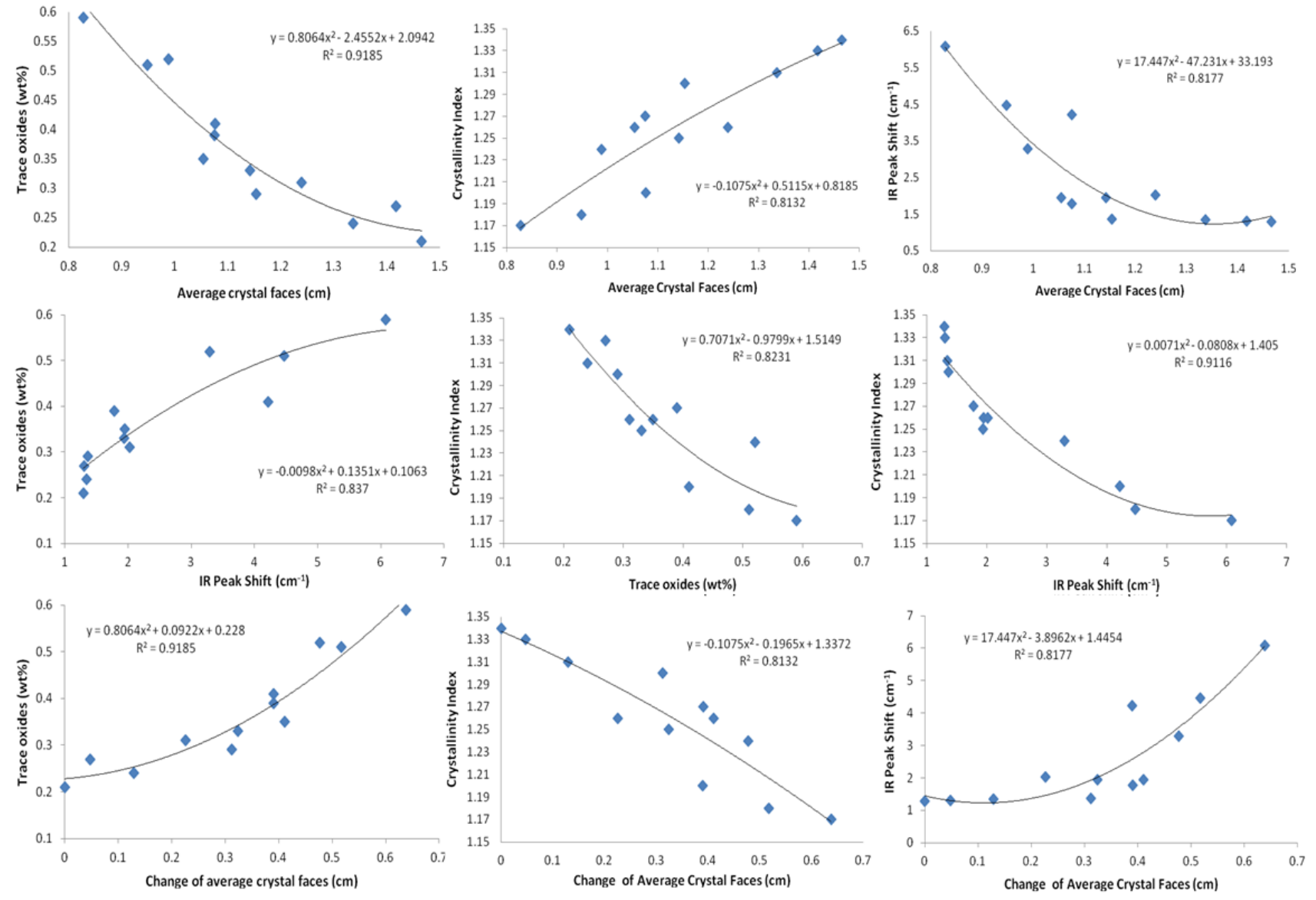

Figure 3. Correlations of different investigated factors of the studied quartz crystals

\section{Acknowledgements}

I thank Directors, National Geophysical Research Institute (NGRI-CSIR), Hyderabad and North East Institute of Science and Technology (NEIST-CSIR), Jorhat for their cooperation during this work. I also thank Dr. G. Parthasarathy, National Geophysical Research Institute (NGRI-CSIR), Hyderabad for his suggestion during the work and Dr. J.R. Chetia, Dibrugarh University, Dibrugarh, for his assistance in the FTIR analysis.

\section{References}

[1] J. B. Lowenstern, W.D. Sinclair, "Exsolved magmatic fluid and its role in the formation of comb-layered quartz at the Cretaceous Logtung W-Mo deposit, Yukon Territory, Canada”, Trans. Royal Soc. Edinburgh, 87, 291-303, (1966).

[2] G. B. Morgan, D. London, R. G. Luedke, "Petrochemistry of late Miocene peraluminous silicic volcanic rocks from the Morococala field, Bolivia”, J. Petrology, 39, 601-632,(1998).
[3] J. Mullis, K. Ramseyer, "Growth related Al-uptake in fissurequartz, Central Alps, Switzerland”, Terra Nostra, 99, 209, (1999).

[4] A. Muller, R. Seltmann, H. J. Behr "Application of cathodoluminescence to magmatic quartz in a tin granite-case study from the Schellerhau Granite Complex, Eastern Erzgebirge, Germany”, Mineralium Deposita, 35, 169-189, (2000).

[5] A.M. Van den Kerkhof, A. Kronz, K. Simon,"Trace element redistributiondistribution in metamorphic quartz and fluid inclusion modification: observations by cathodoluminescence. XVI ECROFI, Porto 2001”, Fac. Ciências Porto, Dep. Geol., Memoria, 7, 447-450, (2001).

[6] A. Kats "Hydrogen in alpha-quartz" Philips Res. Repts., 17, 133279, (1962).

[7] H.U. Bambauer, G.O. Brunner, F. Laves, "Merkmale des OHSpektrums alpiner Quarze ( $3 \mu$-Gebiet)" Schweiz. Mineral. Petrogr. Mitt., 43, 259-268, (1962).

[8] R.D. Aines and G.R. Rossman, "Water in minerals? A peak in the infrared”. J. Geophys. Res., 89, 4059-4071, (1984).

[9] A.K. Kronenberg, S.H. Kirby, R.D. Aines, G.R. Rossmann, "Solubility and diffusional uptake of hydrogen in quartz at high water pressures: implications for hydrolytic weakening in the laboratory and within the earth”, Tectonophysics, 172, 255-271, (1984).

[10] M.R. Rovetta, J.D. Blacic, R.L. Hervig, J.R. Holloway, “An experimental study of hydroxyl in quartz us ing infrared 
spectroscopy and ion microprobe techniques. J., Geophys. Res., 94, 5840-5850, (1989)

[11] H. Bahadur "Sweeping and irradiation effects on hydroxyl defects in crystalline natural quartz.” IEEE Trans. Ultras., Ferroel., Frequ. Control, 41, 820-833, (1994).

[12] Bhaskar J. Saikia, "FTIR estimation of geometrical structure variations in natural $\mathrm{SiO}_{2}$ crystal," Geochimica et Cosmochimica Acta, 74, A.898, (2010).

[13] Phillip D. Ihinger and Stephen I. Zink, "Determination of relative growth rates of natural quartz crystals,” Nature, 404, 865-869, (2000).

[14] J. Injuk and R. Van Grieken, "Sample Preparation for XRF" in Handbook of X-Ray Spectrometry: Methods and Techniques, R.E.Van Grieken, and A.A. Markowicz, (Eds), Marcel Dekker, Inc. New York, NY, pp. 657-692 (1993).

[15] B. Dziunikowski, "Energy Dispersive X-Ray Fluorescence Analysis”, Elsevier, Amsterdam-Oxford (1989).

[16] R. Jenkins, R.W. Gould, D. Gedcke, "Quantitative X-Ray Spectrometry”, Marcel Dekker, New York, Basel (1981).

[17] G. Parthasarathy, "Effect of High-Pressures on the Electrical Resistivity of Natural Zeolites from the Deccan Trap, Mahrashtra, India,” Journal of Applied Geophysics, 58, 321-329, (2002).
[18] J. A. Gadsden, "Infrared Spectra of Minerals and Related Inorganiccompounds,” Butterworths, USA, (1975).

[19] R. M. Hazen and L. W. Finger, "Comparative Crystal Chemistry: Temperature, Pressure, Composition and the Variation of Crystal Structure," J. Wiley \& Sons, London, (1982).

[20] J. Hlavay, S. Jonas, S. Elek, and J. Inczedy, “Characterization of the particle size and the crystallinity of certain minerals by IR spectrophotometry and other instrumental methods-I, investigation on quartz and feldspar,” Clays and Clay Minerals, 25, 451-456, (1977).

[21] J. Hlavay, S. Jonas, S. Elek, and J. Inczedy, "Characterization of the particle size and the crystallinity of certain minerals by IR spectrophotometry and other instrumental methods-II, investigation on quartz and feldspar,” Clays and Clay Minerals, 26, 139-143, (1978)

[22] Bhaskar J. Saikia, G. Parthasarathy, and N. C. Sarmah, "Fourier transform infrared spectroscopic estimation of crystallinity in SiO2 based rocks,” Bull. Mater. Sci., 31, 775-779, (2008).

[23] Rune B. Larsen, Mireille Polve and Gunnar Juve, "Granite pegmatite quartz from Evje-Iveland: trace element chemistry and implications for the formation of high-purity quartz" NGU-Bull. 436, 57-65, (2000). 